\title{
Development of a Selective, Solvent-free Epoxidation of Limonene Using Hydrogen Peroxide and a Tungsten-based Catalyst
}

Mohamad Faiz Mukhtar Gunam Resul, a,b, Ana María López Fernández, ${ }^{a}$ Abdul Rehman $^{\mathrm{a}}$ and Adam P. Harvey ${ }^{\mathrm{a}}$

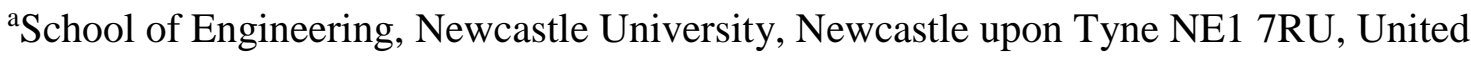
Kingdom

${ }^{\mathrm{b}}$ Department of Chemical and Environmental Engineering, Faculty of Engineering, Universiti Putra Malaysia, 43400 UPM Serdang, Selangor, Malaysia

E-mail: m.f.m.gunam-resul1@newcastle.ac.uk

Keywords: waste biomass, limonene, solvent-free, epoxidation, kinetic study

\begin{abstract}
The development of a limonene epoxidation process using environment-friendly $\mathrm{H}_{2} \mathrm{O}_{2}$, with high $\mathrm{H}_{2} \mathrm{O}_{2}$ conversion ( $\left.\sim 95 \%\right)$ and selectivity to the epoxide (100\%), is reported in this paper. Parametric studies of temperature, oxidant, solvent, acid concentration and sodium sulphate amounts were performed with the focus on establishing a rapid and highly selective process. Approximately $95 \%$ conversion of $\mathrm{H}_{2} \mathrm{O}_{2}$ at $100 \%$ selectivity to limonene-1,2-epoxide was achieved in 15 minutes with a single-step addition of oxidant. The operating conditions included a $323 \mathrm{~K}$ temperature in a solvent-free environment, with a limonene $/ \mathrm{H}_{2} \mathrm{O}_{2} /$ catalyst molar ratio of 4:1:0.005, using a tungsten-based polyoxometalates. To prevent the hydrolysis of the epoxide, the reaction mixture was saturated with sodium sulphate. An acid concentration of lower than $0.04 \mathrm{M}$ was used and found to have significant effect on the selectivity. Kinetic studies were performed to allow modelling of the reaction scheme. The activation energy was determined to be $\sim 36$ $\mathrm{kJ} \mathrm{mol}^{-1}$.
\end{abstract}




\subsection{Introduction}

Waste biomass is of increasing interest as a source of sustainable bio-based industries, as it reduces waste and helps maintain carbon dioxide $\left(\mathrm{CO}_{2}\right)$ neutrality. ${ }^{1}$ Waste biomass-derived limonene, have many applications, especially in the fragrance, flavour and cosmetic industries. ${ }^{2-9}$ Over recent decades, there has been many research into the use of limonene as a chemical feedstock, especially for limonene oxide, a monomer for bio-based polymers. ${ }^{10,11}$ Limonene oxide has many possible uses in the polymer industry and has been investigated as a means of incorporating $\mathrm{CO}_{2}$ into the synthesis of polycarbonates. ${ }^{12-17}$

Epoxidation of alkenes with hydrogen peroxide $\left(\mathrm{H}_{2} \mathrm{O}_{2}\right)$, has been extensively studied. ${ }^{18-29}$ The main benefit of using $\mathrm{H}_{2} \mathrm{O}_{2}$ as an oxidant is its environment-friendly nature; it only produces water $\left(\mathrm{H}_{2} \mathrm{O}\right)$ as a by-product. However, the epoxidation of limonene with $\mathrm{H}_{2} \mathrm{O}_{2}$ remains a challenging area because in the presence of $\mathrm{H}_{2} \mathrm{O}$, the epoxide is prone to hydrolytic ring-opening reaction. The formation of many oxidative by-products and the decomposition of $\mathrm{H}_{2} \mathrm{O}_{2}$ in the presence of a metal catalyst are also common issues. ${ }^{30}$ The epoxidation of limonene using $\mathrm{H}_{2} \mathrm{O}_{2}$ as an oxidant is very exothermic, which is typically mitigated by an excess solvent or by drop-wise addition of the oxidant. This method artificially lowered the rate of reaction and lengthened the reaction time. The use of a solvent also affected the 'greenness' of such process.

Amongst the various types of catalysts used for this epoxidation, a tungsten based polyoxometalates has been shown as effective with $\mathrm{H}_{2} \mathrm{O}_{2}{ }^{31-34}$ This polytungstophosphate has attracted much attention, as it is more active than other transition metals and does not cause substantial $\mathrm{H}_{2} \mathrm{O}_{2}$ decomposition. In this work, a highly selective process was developed for the epoxidation of limonene with $\mathrm{H}_{2} \mathrm{O}_{2}$ in a solvent-free environment. A 
comprehensive parametric study of the various conditions that affect the epoxidation of limonene has been performed. The study has been used to develop a predictive kinetic model incorporating all the processes involved. A competitive reaction rate was able to be achieved by using a single-step addition of oxidant as compared to the typical dropwise method. The exothermicity is mitigated by using limonene itself as a solvent. It is reasoned that this process, utilising a waste biomass-driven limonene, would allow further development of a rapid and intensified process for sustainable bio-based industries. 


\subsection{Experimental}

\subsection{Reagents}

Sodium tungstate dihydrate $\left(\mathrm{Na}_{2} \mathrm{WO}_{4} .2 \mathrm{H}_{2} \mathrm{O}\right), \mathrm{H}_{2} \mathrm{O}_{2}\left(30 \%\right.$ wt. in $\left.\mathrm{H}_{2} \mathrm{O}\right), 42.5 \%$ phosphoric acid $\left(\mathrm{H}_{3} \mathrm{PO}_{4}\right)$, 48.5\% sulphuric acid $\left(\mathrm{H}_{2} \mathrm{SO}_{4}\right)$, anhydrous sodium sulphate $\left(\mathrm{Na}_{2} \mathrm{SO}_{4}\right)$, (R)-Limonene, limonene-1,2-diol, p-cymene, acetonitrile, toluene, 1,2dichloroethane and Adogen 464® phase transfer catalyst were all purchased from SigmaAldrich (Gillingham, UK).

\subsection{Epoxidation reactions}

The polyoxometalates preparation followed the procedure outlined in the literature. ${ }^{35}$ The reaction was performed in a 150 -ml jacketed flask. The temperature was monitored by using a thermocouple, and a water bath supplied the heating. In a typical epoxidation reaction, $\mathrm{H}_{2} \mathrm{O}_{2}(30 \%$ wt, $122 \mathrm{mmol}), \mathrm{Na}_{2} \mathrm{WO}_{4} .2 \mathrm{H}_{2} \mathrm{O}(0.2 \mathrm{~g}), \mathrm{H}_{3} \mathrm{PO}_{4}(42.5 \%$, $0.06 \mathrm{mmol})$ and $\mathrm{Na}_{2} \mathrm{SO}_{4}(5.2 \mathrm{~g})$ were stirred for 30 minutes to form the catalyst complex. $\mathrm{H}_{2} \mathrm{SO}_{4}(48.5 \%)$ was used to adjust the initial $\mathrm{pH}$ of the aqueous phase (4 mmol). The reaction began when limonene was added $(122 \mathrm{mmol})$, together with a phase transfer catalyst, Adogen 464® $(1 \mathrm{~g})$. In the reactions in the presence of a solvent, toluene was typically used (100-500 mol\%). Following the completion, the reaction mixture was placed in a separating funnel. To the organic phase, $0.1 \mathrm{M}$ sodium chloride $(\mathrm{NaCl})$ was added to destabilise the phase transfer catalyst. The separated organic phase was dried using an anhydrous $\mathrm{Na}_{2} \mathrm{SO}_{4}$. A vacuum evaporator fitted with a silicone oil bath was used to separate limonene from limonene oxide at a temperature of $423 \mathrm{~K}$ and a pressure lower 
than 50 mbar. The purity of the products obtained as confirmed by Gas Chromatography (GC) is more than $\sim 98 \%$.

\subsection{In situ Fourier transform infra-red (FTIR) analysis}

The reaction was continuously monitored by using the React IR-4000 Fourier transform infra-red (FTIR) analysis equipment from Mettler Toledo (USA). The scanning ranged from 4000 to $650 \mathrm{~cm}^{-1}$, with the sampling typically performed every $15 \mathrm{sec}$. Peaks for limonene and limonene oxide were monitored at the wavelengths of $1150 \mathrm{~cm}^{-1}$ and $841 \mathrm{~cm}^{-1}$, respectively.

\subsection{Product analysis (gas chromatography)}

Analysis using gas chromatography (GC) was performed to monitor the formation of by-products with higher accuracy. Organic samples were taken periodically during the reaction at designated time intervals for GC analysis. About $40 \mu \mathrm{L}$ of each sample was measured into a $2-\mathrm{mL}$ GC vial and diluted with $1960 \mu \mathrm{L}$ of chloroform $\left(\mathrm{CHCl}_{3}\right)$ to be within the range of the flame ionisation detector (FID). About $10 \mathrm{mg}$ of naphthalene was later added to the diluted sample. A calibration curve was prepared beforehand to calibrate the GC responses to the internal standard and all reagents and possible products. About $0.5 \mu \mathrm{L}$ of the sample mixture was injected into the column manually, using a $5-\mu \mathrm{L}$ GC syringe (SGE). The samples were analysed by using a 5890 Hewlett Packard Series II GC equipped with a CP Wax Capillary column (BPX70). Reaction conversion and yield were calculated from GC analysis based on the internal standard response factor. Pure sample of limonene, limonene-1,2-epoxide, limonene-1,2-diol, and limonene-bis-epoxide were 
used as standards to calculate the response factor. Analysis from parallel experiments shows less than $\sim 2 \%$ error for mean value. The following expression determined the conversion:

$$
\text { Conversion }(\%)=\frac{C_{0}-C_{i}}{C_{0}} \times 100 \%
$$

Where $\mathrm{C}_{0}$ is the initial concentration of limonene and $\mathrm{C}_{\mathrm{i}}$ is the concentration of limonene in the sample as determined by GC. When $\mathrm{H}_{2} \mathrm{O}_{2}$ is the limiting reactant, the concentration of $\mathrm{H}_{2} \mathrm{O}_{2}$ and its conversion were determined by the titration method. The yield of products is calculated using the following expression:

$$
\text { Yield }(\%)=\frac{X_{i}}{C_{0}} \times 100 \%
$$

Where $\mathrm{X}_{\mathrm{i}}$ is the concentration of products in the sample as determined by GC. 


\subsection{Results and Discussion}

\subsection{Reaction scheme}

The catalytic epoxidation of limonene with $\mathrm{H}_{2} \mathrm{O}_{2}$ could generate many oxidative products (Figure 1).

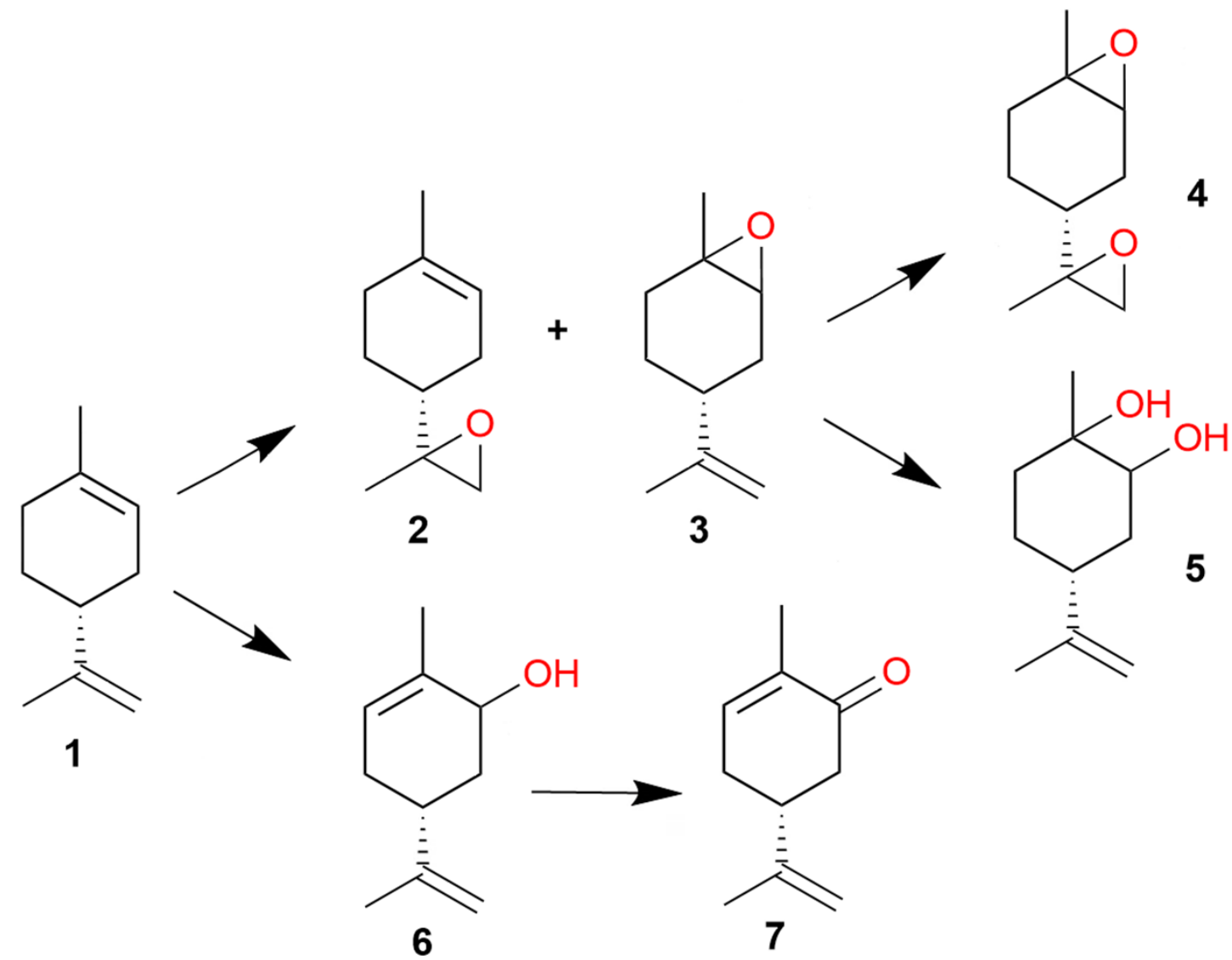

Figure 1. Typical reaction scheme for the epoxidation of limonene with hydrogen peroxide $\left(\mathrm{H}_{2} \mathrm{O}_{2}\right)$ as oxidant. Limonene $\mathbf{1}$, limonene-8,9-epoxide $\mathbf{2}$, limonene-1,2-epoxide 3, limonene-bis-epoxide 4, limonene-1,2-diol 5, carveol 6 and carvone 7.

Epoxidation of limonene with $\mathrm{H}_{2} \mathrm{O}_{2}$ would produce both limonene-8,9-epoxide and limonene-1,2-epoxide (a mixture of cis- and trans-). Due to the electrophilic nature of the oxidant, epoxidation would more likely occur at more substituted double bonds, causing limonene-1,2-epoxide to be the primary product. ${ }^{22}$ Limonene-bis-epoxide (a 
mixture of four isomers) would be produced by the epoxidation of external double bonds of limonene-1,2-epoxide. Moreover, limonene-1,2-epoxide could undergo hydrolytic decomposition to form limonene-1,2-diol in the presence of acid $(\mathrm{H}+)$ and $\mathrm{H}_{2} \mathrm{O}$. Limonene could also in principle undergo allylic oxidation to form carveol, which could be further converted to carvone by oxidative dehydrogenation. 


\subsection{Kinetics and modelling}

To model the epoxidation reaction of limonene with $\mathrm{H}_{2} \mathrm{O}_{2}$, the reaction scheme in Figure 2 is proposed to summarise the overall reactions.

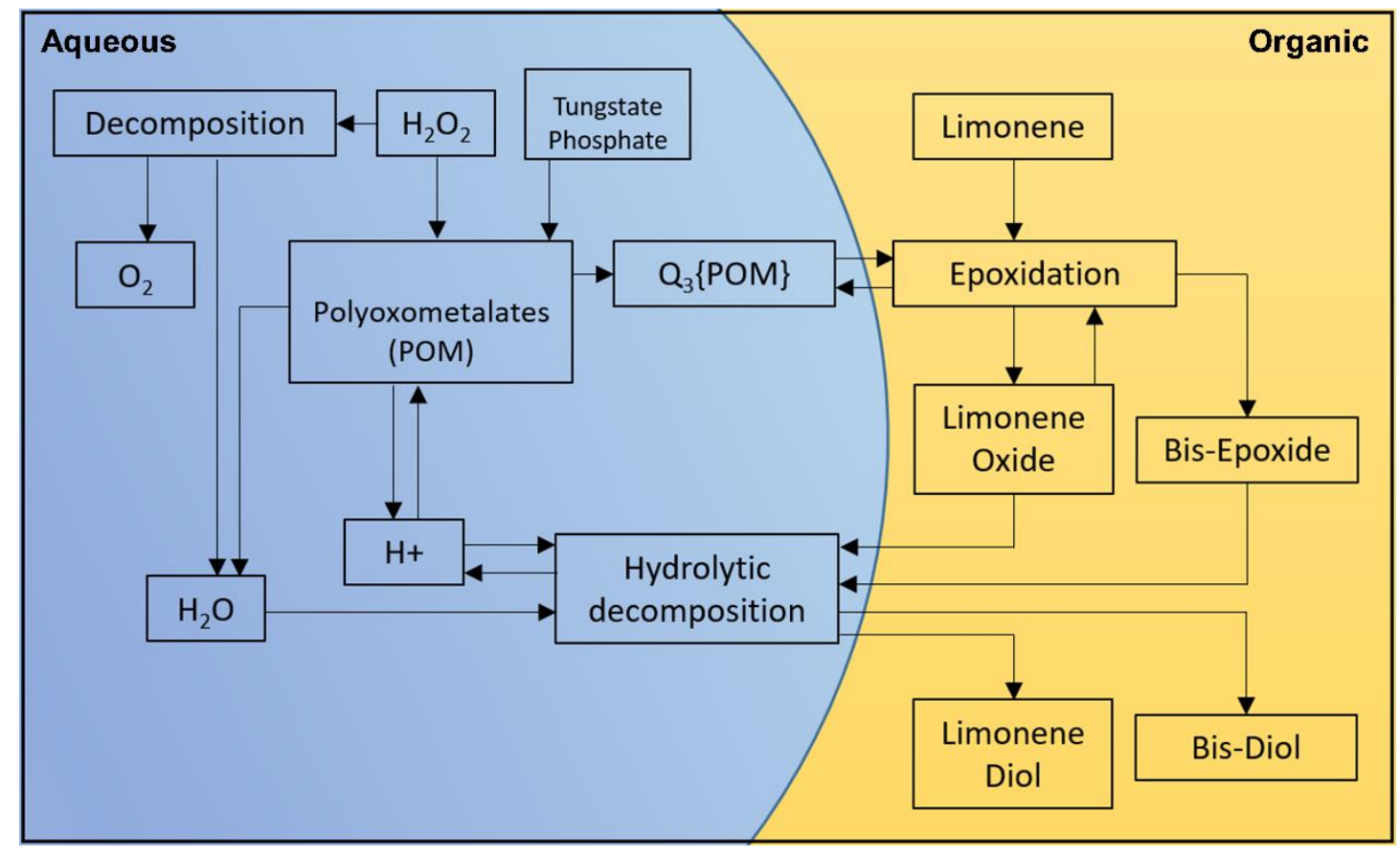

Figure 2. Proposed overall reaction scheme for the epoxidation of limonene, the formation of polyoxometalates, the decomposition of $\mathrm{H}_{2} \mathrm{O}_{2}$ and the hydrolytic decomposition of the epoxides. The schematic diagram visualises the phase where each reaction occurs (blue background: aqueous phase, gold background: organic phase).

Figure 2 shows that the polytungstophosphate $\left\{\mathrm{PO}_{4}\left[\mathrm{WO}\left(\mathrm{O}_{2}\right)_{2}\right]_{4}\right\}^{3-}$ formed from $\mathrm{H}_{2} \mathrm{O}_{2}$, tungstate and phosphate shuttles to and from the organic phase via a phase transfer catalyst $\left(\mathrm{Q}^{+}\right)$. The details of the mechanism are elaborated in the literature. ${ }^{33,36,37}$ The active oxygen is transferred to both limonene and limonene oxide via the epoxidation reaction. The $\mathrm{H}+$ ions participate in the formation of the polyoxometalates and the protonic attack on the epoxides at the interphase. The epoxides form a diol in the presence of $\mathrm{H}_{2} \mathrm{O}$ (nucleophile), following the protonic attack. The model also considers the decomposition of $\mathrm{H}_{2} \mathrm{O}_{2}$ as it will likely occur in the reaction. 
Therefore, the rate laws for all the reactions considered by the model can be written as follows:

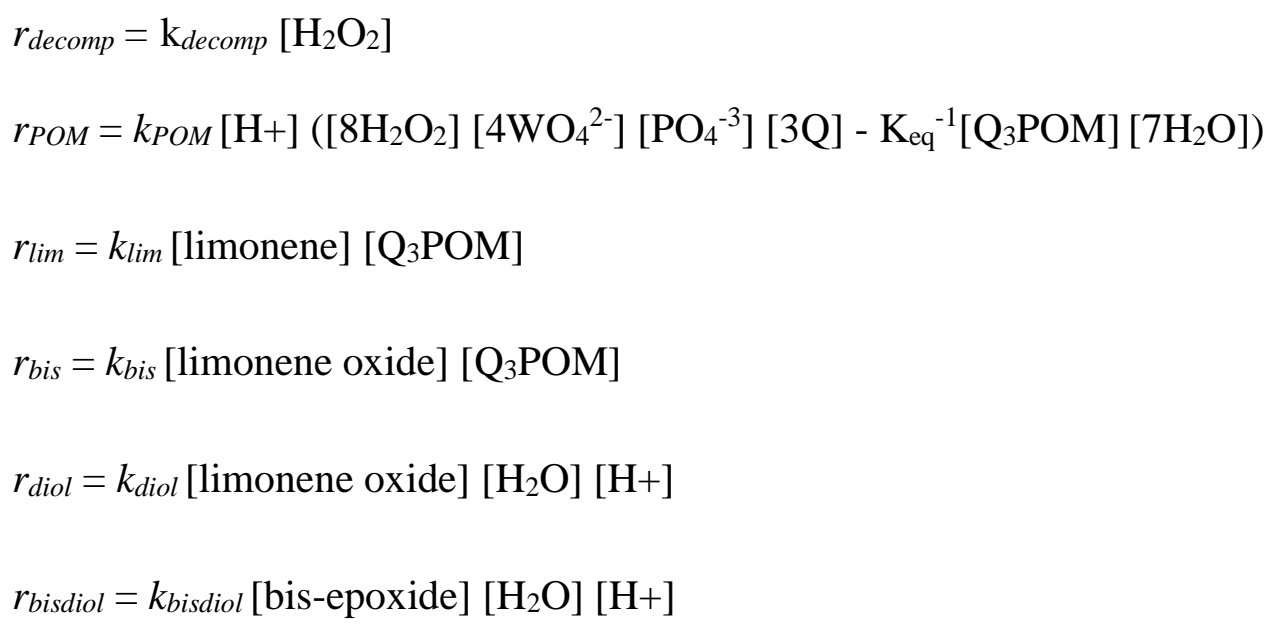

In this work, the kinetic study was performed by applying the initial rate method based on pseudo first-order conditions. A prior mixing study ensured that the kinetic study was performed without mass transfer limitation.

To determine the reaction order with respect to the catalyst, the concentrations of the catalysts precursor, $\mathrm{Na}_{2} \mathrm{WO}_{4}$ were varied between $0.003 \mathrm{M}$ and $0.009 \mathrm{M}$. The initial concentrations of limonene, $\mathrm{H}_{2} \mathrm{O}_{2}$ and solvent were kept constant. 

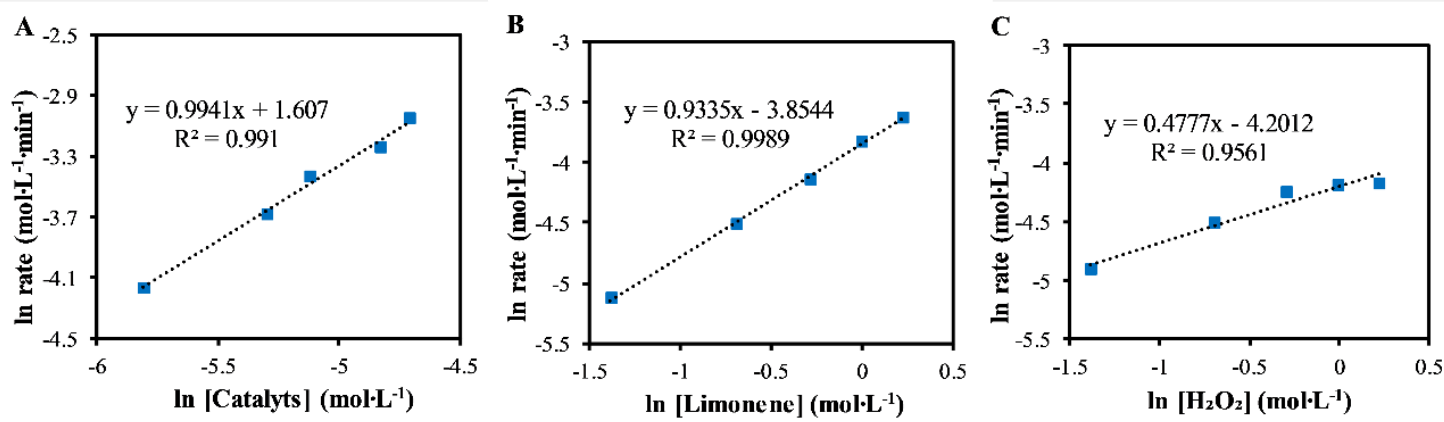

Figure 3. The plot of the natural $\log$ between the initial reaction rate and $\mathrm{A}$ ) catalyst concentration. B) limonene concentration. C) $\mathrm{H}_{2} \mathrm{O}_{2}$ concentration.

The plot of the natural log between the initial rates and the catalyst concentration produces a straight line with a gradient of $\sim 1$, indicating that the reaction is not diffusion limited (Figure 3(A)). The reaction order with respect to limonene was determined by varying the initial concentration of limonene from $0.25 \mathrm{M}$ to $1.25 \mathrm{M}$. The concentrations of $\mathrm{H}_{2} \mathrm{O}_{2}$ were kept constant and in excess. Figure 3(B) confirms a first-order reaction from the gradient of the plot of the natural log between the initial rates and limonene concentration.

The reaction order with respect to $\mathrm{H}_{2} \mathrm{O}_{2}$ was determined by varying the initial concentration of $\mathrm{H}_{2} \mathrm{O}_{2}$ from $0.25 \mathrm{M}$ to $1.25 \mathrm{M}$. The initial concentration of limonene was kept constant and in excess. The gradient obtained from Figure 3(C) shows a fractional reaction order of $\sim 0.5$, indicating a complex mechanism. According to Figure 2 and Equation (4), increasing the concentration of $\mathrm{H}_{2} \mathrm{O}_{2}$ increases the formation of the polyoxometalates but is limited to the concentration of tungstate and phosphate. This also implied that the epoxidation of limonene, as shown by Equation (5), would most probably be the rate-determining step. Yadav and Satoskar reported similar behaviour for the epoxidation of undecylenic acid, where the rate was independent of the $\mathrm{H}_{2} \mathrm{O}_{2}$ 
concentration when the ratio of the $\left[\mathrm{H}_{2} \mathrm{O}_{2}\right] /$ [catalyst] was high. ${ }^{37}$ Kamata et al. also found an apparent zero-order dependence on the $\mathrm{H}_{2} \mathrm{O}_{2}$ concentration for the epoxidation of alkene. $^{38}$

\subsection{Effect of temperature}

The effects of temperature on the epoxidation of limonene were investigated. The temperature varied between $303 \mathrm{~K}$ and $333 \mathrm{~K}$.

A

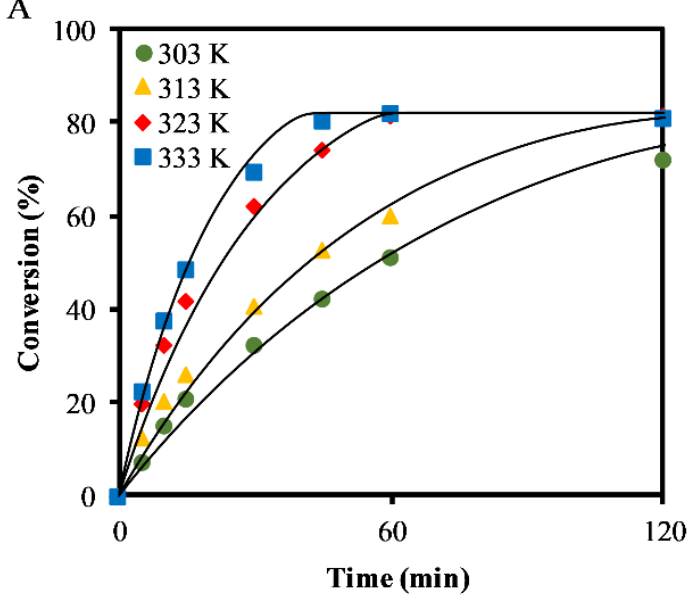

C

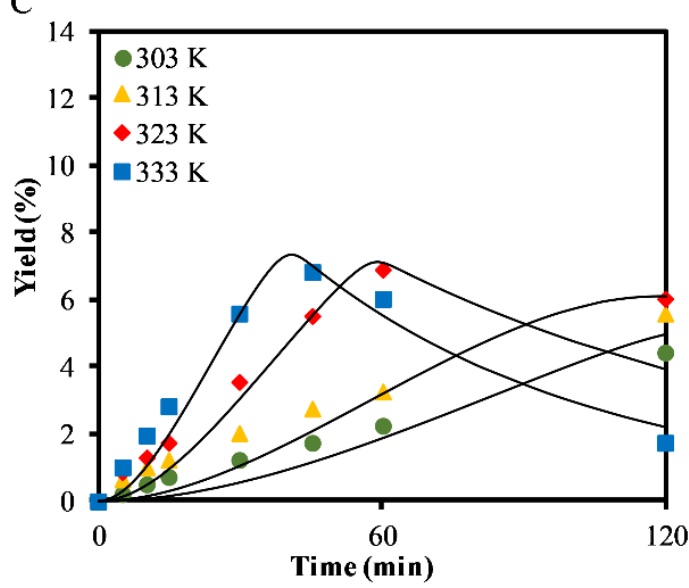

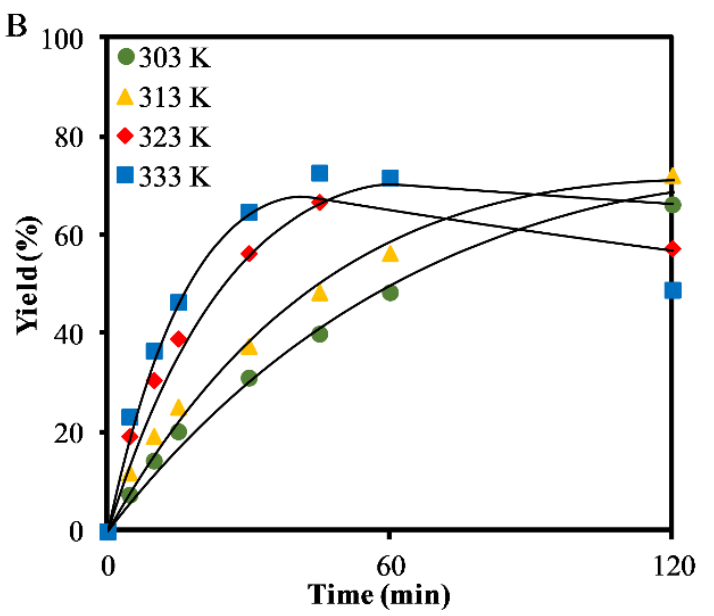

D

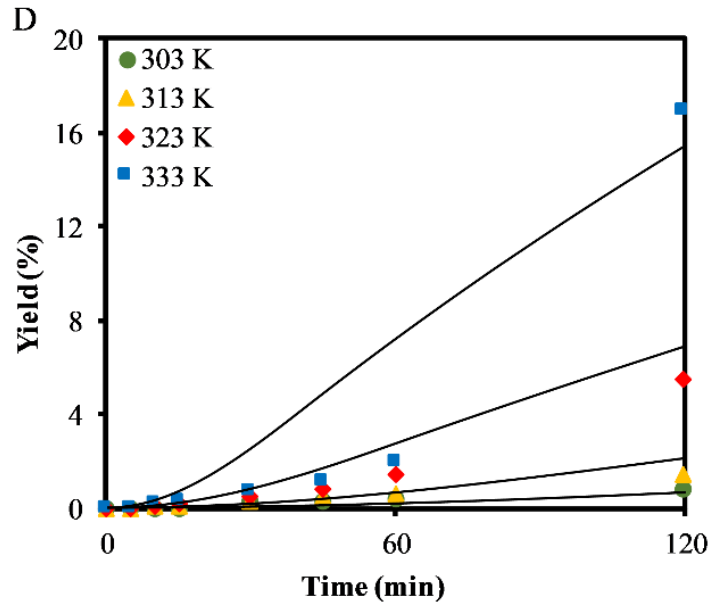

Figure 4. The effects of temperature on limonene epoxidation. A) conversion of limonene, B) yield of limonene oxide, $\mathrm{C}$ ) yield of bis-epoxide and $\mathrm{D})$ yield of limonene diol. Reaction conditions: limonene (1.25 M), $\mathrm{H}_{2} \mathrm{O}_{2}(1.25 \mathrm{M}), \mathrm{Na}_{2} \mathrm{WO}_{4}(0.006 \mathrm{M}), \mathrm{H}_{2} \mathrm{SO}_{4}(0.06 \mathrm{M})$ and toluene $(500 \mathrm{~mol} \%)$. The lines are fitted to the kinetic model by using Equations (3)-(8) and the rate constant in Table 1. 
The conversion of limonene reaches a maximum of $80 \%$ at a reaction time of 120 min for all temperatures (Figure 4(A)). However, at a temperature higher than $323 \mathrm{~K}$, the yield of limonene oxide and bis-epoxide attains a maximum of $73 \%$ and $7 \%$, respectively before gradually decreasing (Figure 4(B) and 4(C). The decrease in both limonene oxide and bis-epoxide yields over the reaction time can be explained by the rate of hydrolysis, which results in the formation of limonene diol and bis-diol, respectively. On the other hand, the yield of limonene diol at $333 \mathrm{~K}$ is over $15 \%$ at a reaction time of $120 \mathrm{~min}$ (Figure 4(D)). This result is more than double the yield at $323 \mathrm{~K}(7 \%)$. The kinetic model is able to predict the formation of bis-epoxide and limonene diol at temperatures up to $333 \mathrm{~K}$ and validates the experimental data. To ensure the highest selectivity towards the formation of limonene oxide, it is suggested that the epoxidation reaction be performed at a temperature below $323 \mathrm{~K}$.

The Arrhenius dependence for the formation of the desired product, limonene oxide and a major by-product, limonene diol was determined by varying the reaction temperature between $303 \mathrm{~K}$ and $333 \mathrm{~K}$. Figure 5 shows the temperature dependence of limonene oxide and limonene diol formation as plots of $\ln \left(k_{\text {epox }}\right)$ and $\ln \left(k_{\text {diol }}\right)$ versus $1 / \mathrm{T}$. 


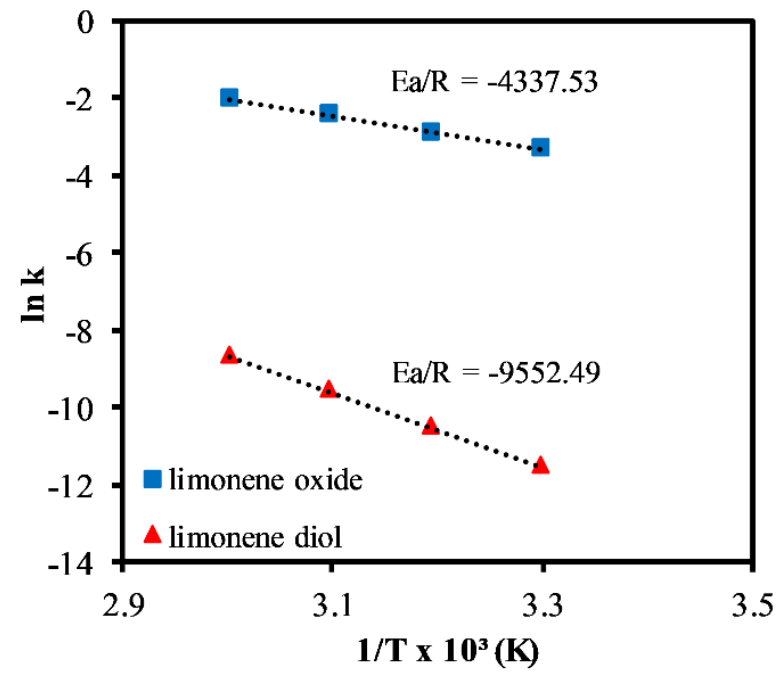

Figure 5. Temperature dependence of the rate constant for the formation of limonene oxide and limonene diol.

The activation energy for the formation of limonene oxide obtained from the gradient of Figure 5 was determined to be $\sim 36 \mathrm{~kJ} \mathrm{~mol}^{-1}$. This figure is higher than the 16 $\mathrm{kJ} \cdot \mathrm{mol}^{-1}$ reported by Cagnoli et al. ${ }^{20}$ However, Villa et al. reported a much higher value $\left(76 \mathrm{~kJ} \mathrm{~mol}^{-1}\right)$, but they had used a heterogeneous catalyst. ${ }^{25}$ On the other hand, the activation energy for the formation of limonene diol was determined to be $\sim 79 \mathrm{~kJ} \mathrm{~mol}^{-1}$. This result confirms that the formation of a by-product, limonene diol proceeds slowly at a lower temperature compared with limonene oxide. However, at a temperature above $323 \mathrm{~K}$, the reaction rate becomes more significant, resulting in a higher yield of limonene diol. Table 1 lists the kinetic parameters obtained from the study. 
Table 1. The pre-exponential factor and the activation energy for the formation of limonene oxide, bis-epoxide and limonene diol.

Activation energy $\left(\mathrm{kJ} \mathrm{mol}^{-1}\right)$

Pre-exponential factor

\begin{tabular}{lccc}
\cline { 3 - 4 } & & This work & References \\
\hline $\mathrm{k}_{\text {epox }}{ }^{\mathrm{a}}$ & $5.9 \times 10^{4}$ & 36 & $16^{20}$ \\
& & & $76^{25}$ \\
$\mathrm{k}_{\text {bis }}{ }^{\mathrm{a}}$ & $8.6 \times 10^{4}$ & 43 & \\
$\mathrm{k}_{\text {diol }}{ }^{\mathrm{b}}$ & $4.9 \times 10^{8}$ & 79 & \\
\hline
\end{tabular}

${ }^{\mathrm{a}}$ unit of $\mathrm{L}^{1} \mathrm{~mol}^{-1} \mathrm{~s}^{-1}$; ${ }^{\mathrm{b}}$ unit of $\mathrm{L}^{2} \mathrm{~mol}^{-2} \mathrm{~s}^{-1}$ 


\subsection{Effect of oxidant amount}

The effect of the oxidant amount was studied by varying the concentration of $\mathrm{H}_{2} \mathrm{O}_{2}$ from $100 \mathrm{~mol} \%$ to $200 \mathrm{~mol} \%$.
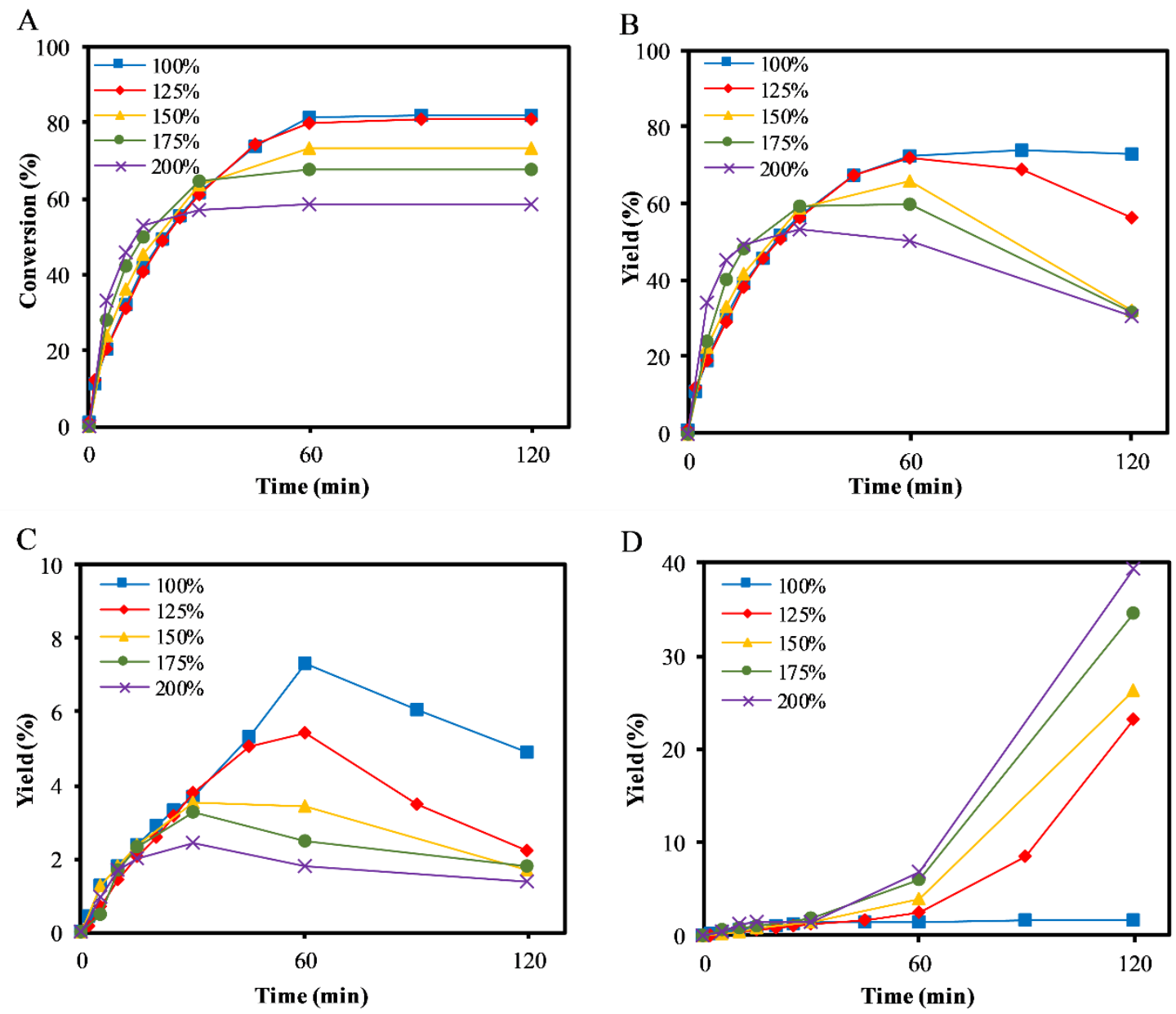

Figure 6. The effect of the oxidant amount on limonene epoxidation. (A) conversion of limonene, (B) yield of limonene oxide, (C) yield of bis-epoxide and (D) yield of limonene diol. Reaction conditions: temperature $(323 \mathrm{~K})$, limonene $(1.25 \mathrm{M}), \mathrm{Na}_{2} \mathrm{WO}_{4}(0.006 \mathrm{M}), \mathrm{H}_{2} \mathrm{SO}_{4}(0.06 \mathrm{M})$ and toluene $(500 \mathrm{~mol} \%)$.

The conversion of limonene decreases from $82 \%$ to $58 \%$ when the oxidant amount is increased from $100 \mathrm{~mol} \%$ to $200 \mathrm{~mol} \%$ (Figure 6(A)). Since there is no significant decomposition of $\mathrm{H}_{2} \mathrm{O}_{2}$ during the catalyst preparation, the decrease in limonene conversion, might be attributed to the dilution of the polyoxometalates in the aqueous 
phase. This finding is similar to the observation of Wang and Huang, who reported a decrease in conversion for 1,7-octadiene with an increasing amount of oxidant $\left(\mathrm{H}_{2} \mathrm{O}_{2}\right) .{ }^{39}$ The yield of limonene oxide also decreases with an increasing oxidant amount (Figure 6(B)). The yields are $74 \%$ and $30 \%$ for oxidant amounts of $100 \mathrm{~mol} \%$ and $200 \mathrm{~mol} \%$, respectively. Above $125 \mathrm{~mol} \%$, the yield of limonene oxide attains a maximum before decreasing with time, becoming more pronounced as the oxidant amount increases.

The yield of bis-epoxide is highest when the oxidant amount used is $100 \mathrm{~mol} \%$ (Figure $6(\mathrm{C})$ ). The yield attains a maximum of $8 \%$ before gradually decreasing. Interestingly, increasing the oxidant amount from $100 \mathrm{~mol} \%$ to $200 \mathrm{~mol} \%$ decreases the yield of bis-epoxide. This finding is in contrast with the observation of Takumi et al. ${ }^{40}$ where they reported an increase of up to $40 \%$ yield of bis-epoxide with an increasing oxidant amount, which might be attributed to the lower temperature and acid concentration used in their study.

The yield of limonene diol increases dramatically with an increasing oxidant amount (Figure 6(D)). The yield at a reaction time of 120 min rises from $8 \%$ to about $40 \%$ with an increasing oxidant. The formation of diol is influenced by the concentrations of both $\mathrm{H}+$ and $\mathrm{H}_{2} \mathrm{O}$. The increased $\mathrm{H}_{2} \mathrm{O}$ concentration is in proportion to the increase in the oxidant amount since $30 \%$ (wt/wt) $\mathrm{H}_{2} \mathrm{O}_{2}$ solution is used. To maintain the highest selectivity towards limonene oxide and to minimise the formation of limonene diol, using an equivalent amount (100 mol\%) of oxidant to limonene is therefore suggested. 


\subsection{Effect of sodium sulphate $\left(\mathrm{Na}_{2} \mathrm{SO}_{4}\right)$}

The presence of $\mathrm{H}_{2} \mathrm{O}$ in an $\mathrm{H}_{2} \mathrm{O}_{2}$ solution was found to adversely affect the selectivity of limonene oxide due to the hydrolysis of the epoxide ring. Many methods have been developed to suppress the hydrolysis process, including the addition of an inorganic salt, $\mathrm{Na}_{2} \mathrm{SO}_{4}$, which has been found to improve the selectivity of terpenes oxide. ${ }^{30,35}$ In this work, the effect of $\mathrm{Na}_{2} \mathrm{SO}_{4}$ to limonene epoxidation was investigated. The amount of $\mathrm{Na}_{2} \mathrm{SO}_{4}$ used varied from $2.5 \mathrm{~g}$ to $7.5 \mathrm{~g}$.
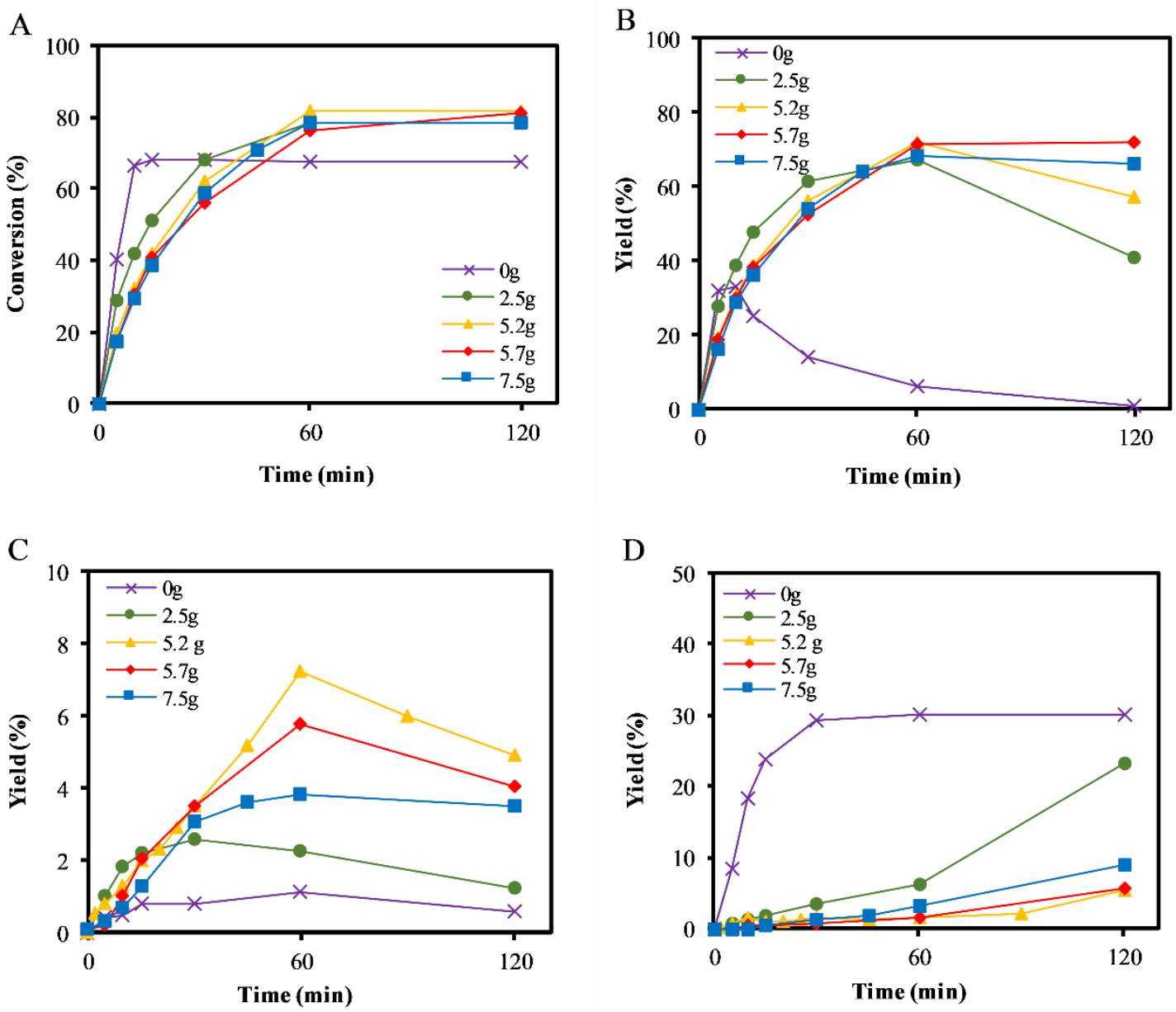

Figure 7. The effect of the $\mathrm{Na}_{2} \mathrm{SO}_{4}$ amount on limonene epoxidation. (A) conversion of limonene, (B) yield of limonene oxide, (C) yield of bis-epoxide and (D) yield of limonene diol. Reaction conditions: temperature $(323 \mathrm{~K})$, limonene $(1.25 \mathrm{M}), \mathrm{H}_{2} \mathrm{O}_{2}(1.25 \mathrm{M}), \mathrm{Na}_{2} \mathrm{WO}_{4}(0.006 \mathrm{M}), \mathrm{H}_{2} \mathrm{SO}_{4}$ $(0.06 \mathrm{M})$ and toluene $(500 \mathrm{~mol} \%)$. 
In the absence of $\mathrm{Na}_{2} \mathrm{SO}_{4}$, the $\mathrm{pH}$ of the aqueous phase is lower; thus, more protons $(\mathrm{H}+)$ are present in the system, causing an increase in the reaction rate (Figure 7(A). On the other hand, the addition of $\mathrm{Na}_{2} \mathrm{SO}_{4}$ increases the yield of limonene oxide (Figure 7(B)). The yield at a reaction time of 120 min increases from less than 5\% to $75 \%$ when the amount of $\mathrm{Na}_{2} \mathrm{SO}_{4}$ is increased from $0 \mathrm{~g}$ to $5.7 \mathrm{~g}$. There is no decrease in the yield of limonene oxide over time when more than $5.7 \mathrm{~g}$ of $\mathrm{Na}_{2} \mathrm{SO}_{4}$ is used. In the presence of $\mathrm{Na}_{2} \mathrm{SO}_{4}$, the ionic strength of the aqueous phase increases ${ }^{30}$. Although the mechanism of the salt effect is difficult to determine, it is postulated that the salt ionised into its respective ions, inducing a 'salting-out' process ${ }^{41}$. The ions repulse nonelectrolyte compound such as limonene oxide in the aqueous phase, minimising the epoxide solubility at the interphase, which in turn suppressed the hydrolysis process.

A slight limitation of this effect can be seen in Figure 7(C), where the hydrolysis of bis-epoxide is only suppressed at a much higher salt concentration $(7.5 \mathrm{~g})$. This might be due to the higher affinity of bis-epoxide towards the aqueous phase due to the presence of two epoxide ring in its molecule. Figure 7(D) confirms the importance of $\mathrm{Na}_{2} \mathrm{SO}_{4}$, where the yield of limonene diol decreases from $30 \%$ to about $5 \%$ with an increasing amount of $\mathrm{Na}_{2} \mathrm{SO}_{4}$. The utilisation of $\mathrm{Na}_{2} \mathrm{SO}_{4}$ effectively reduces the hydrolysis of limonene oxide. The epoxidation of limonene using $\mathrm{H}_{2} \mathrm{O}_{2}$ achieves the highest selectivity to limonene oxide when the aqueous phase is $100 \%$ saturated with $\mathrm{Na}_{2} \mathrm{SO}_{4}(5.7 \mathrm{~g})$. 


\subsection{Effect of acid concentration}

The concentration of acid $\left(\mathrm{H}_{2} \mathrm{SO}_{4}\right)$ in the reaction media affects the stability of the catalyst $^{30,31,34,40,42,43}$. The effect of acid on limonene epoxidation was studied by varying the initial concentration of $\mathrm{H}_{2} \mathrm{SO}_{4}$ from $0.02 \mathrm{M}$ to $0.06 \mathrm{M}$. The initial $\mathrm{pH}$ for all cases was lower than 1.

A

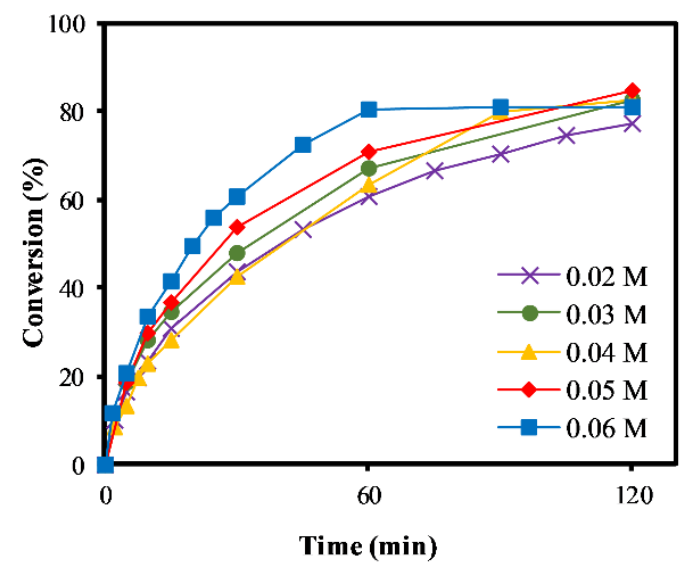

$\mathrm{C}$

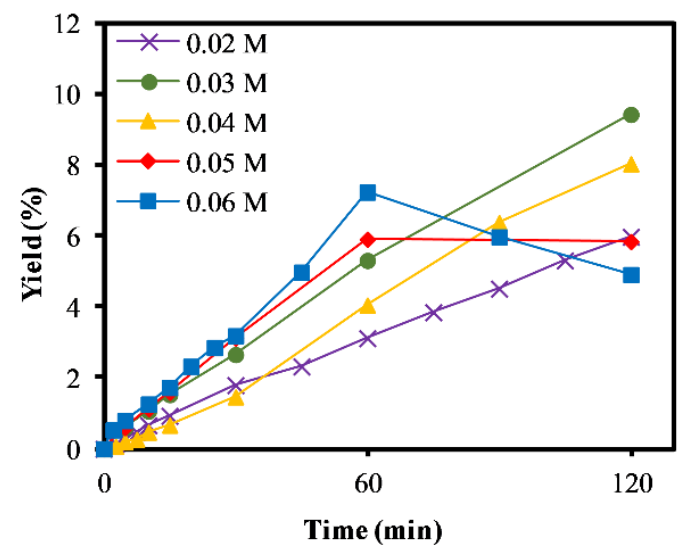

B

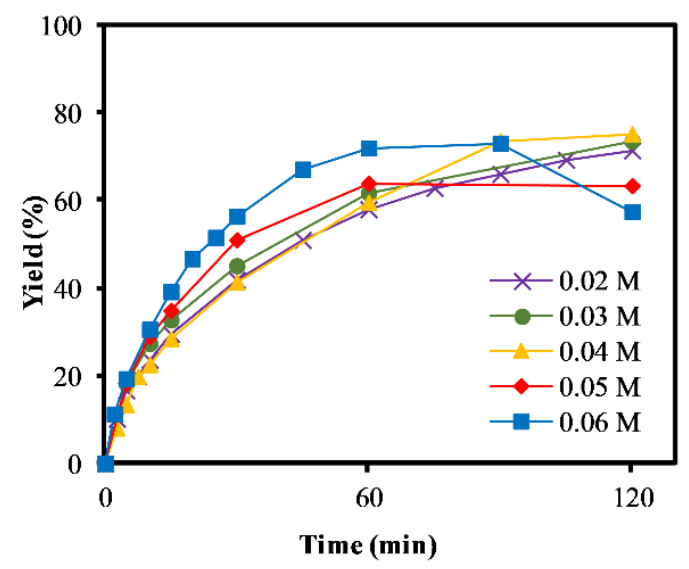

D

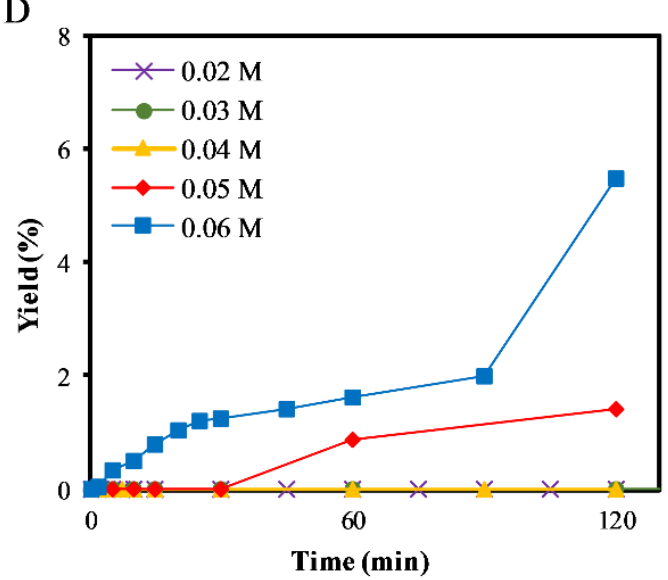

Figure 8. The effect of acid concentration on limonene epoxidation. A) conversion of limonene, B) yield of limonene oxide, C) yield of bis-epoxide and D) yield of limonene diol. Reaction conditions: temperature $(323 \mathrm{~K})$, limonene $(1.25 \mathrm{M}), \mathrm{H}_{2} \mathrm{O}_{2}(1.25 \mathrm{M}), \mathrm{Na}_{2} \mathrm{WO}_{4}(0.006 \mathrm{M})$ and toluene $(500 \mathrm{~mol} \%)$.

The conversion of limonene reaches $80 \%$ for all acid concentrations at a reaction time of 120 min (Figure 8(A)). The yield of limonene oxide and bis-epoxide rises from 
$57 \%$ to $71 \%$ and $5 \%$ to $10 \%$, respectively when the acid concentration is decreased from $0.06 \mathrm{M}$ to $0.02 \mathrm{M}$ (Figure $8(\mathrm{~B})$ and $8(\mathrm{C})$. At an acid concentration of more than $0.05 \mathrm{M}$, the yield of bis-epoxide attains a maximum before gradually decreasing. The yield of limonene diol is only quantifiable when the acid concentration is more than $0.05 \mathrm{M}$ (Figure 8(D)). At an acid concentration lower than $0.04 \mathrm{M}$, no limonene diol is present in the reaction mixture over the reaction time.

In all cases, the $\mathrm{pH}$ increases during the reaction. This might be due to the formation of $\mathrm{H}_{2} \mathrm{O}$ as $\mathrm{H}_{2} \mathrm{O}_{2}$ was progressively consumed. The final $\mathrm{pH}$ was above 2 when the acid concentration is less than $0.05 \mathrm{M}$, which shows the reduction in $\mathrm{H}+$ concentration. The reduced acidity positively affects the selectivity of the epoxide as the acid-catalysed hydrolysis was suppressed. In this regard, a pH buffer might be detrimental to the epoxide selectivity since acid-catalysed hydrolysis could be enhanced throughout the reaction.

Acid concentration plays a vital role in the epoxidation of limonene using a tungsten-based polyoxometalates. The highest selectivity towards limonene oxide with little to no diol formation can be achieved by optimising the acid concentration used in the reaction. The acid-catalysed regio-isomerisation of limonene to form products such as terpinolene and terpinene has been reported. ${ }^{44}$ However, the absence of such products in this work might be due to the lower acid concentration used and the different catalyst employed. It should be noted that prior control experiments were performed without the addition of $\mathrm{H}_{2} \mathrm{SO}_{4}$. Without the addition of acid, the initial $\mathrm{pH}$ of the aqueous phase is about 4.0. No conversion of limonene is detected throughout the reaction time. 


\subsection{Effects of solvents}

The reactivity of limonene epoxidation reaction is related to the nature and the polarity of solvents. Here, four different solvents, ranging from non-polar to polar, were used and compared for practical applications (Figure 9). A greener solvent, p-cymene was also evaluated. Additionally, a solvent-free system was studied by using limonene in a higher molar ratio (> $200 \mathrm{~mol} \%$ ).

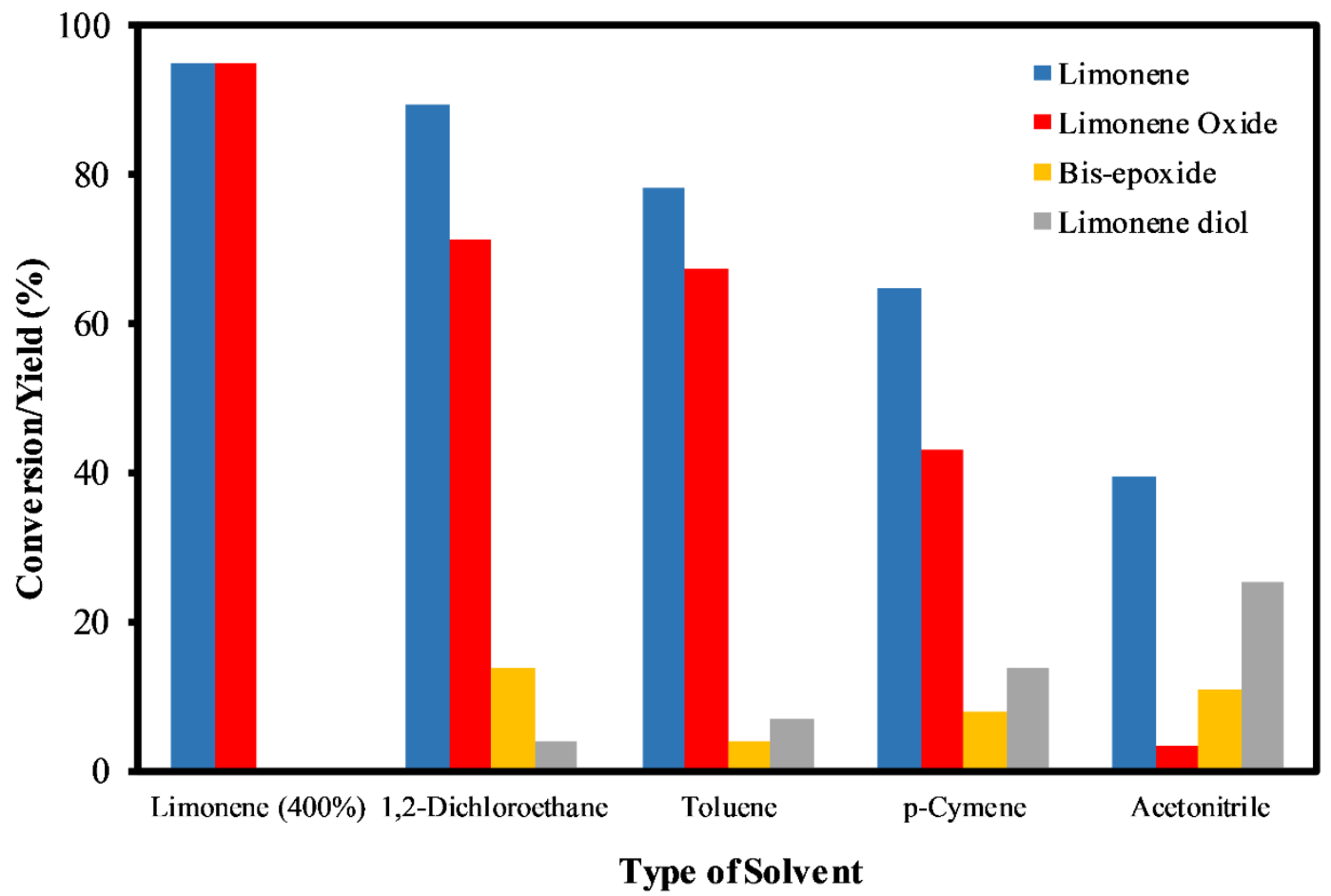

Figure 9. The effects of solvents on limonene epoxidation. Reaction conditions: temperature (323 $\mathrm{K})$, limonene (1.25 M), $\mathrm{H}_{2} \mathrm{O}_{2}(1.25 \mathrm{M}), \mathrm{Na}_{2} \mathrm{WO}_{4}(0.006 \mathrm{M}), \mathrm{H}_{2} \mathrm{SO}_{4}(0.06 \mathrm{M})$, reaction time (120 $\mathrm{min}$ ) and solvent amount (500 $\mathrm{mol} \%$ ) for each solvent. Limonene is represented by the calculated conversion whereby limonene oxide, bis-epoxide and limonene diol are represented by the calculated yield.

The conversion of limonene increases when the solvents are used in the following order: acetonitrile $(39 \%),<$ p-cymene $(65 \%),<$ toluene $(78 \%)$ and $<1,2$-dichloroethane (89\%). The chlorinated solvent, 1,2-dichloroethane, significantly increases the conversion of limonene compared with the other tested solvents. However, the selectivity towards limonene oxide is reduced due to the formation of both bis-epoxide and limonene 
diol. The yield of limonene diol using this solvent is the lowest of all the solvents. Toluene has been used throughout this study, and it is found to have a lower activity than that of 1,2-dichloroethane. Although the polarity of toluene is lower than that of 1,2dichloroethane, the higher activity of the latter might be due to the chloro-compound present in the solvent.

The selectivity to limonene oxide in p-cymene is lower than in toluene and in 1,2dichloroethane, where the yield of limonene diol is slightly higher (14\%). The conversion of limonene is found to be lowest when acetonitrile is used. The selectivity towards limonene oxide is poor, which in turn results in a much higher yield of limonene diol $(25 \%)$. This outcome might be due to the higher polarity of acetonitrile that enhances the hydrolysis of the epoxide.

High selectivity to limonene oxide and high $\mathrm{H}_{2} \mathrm{O}_{2}$ conversion are obtained when limonene is used in a higher molar ratio than $\mathrm{H}_{2} \mathrm{O}_{2}$ without any solvent (Figure 10). The conversion and yield were determined based on the concentration of $\mathrm{H}_{2} \mathrm{O}_{2}$ as the limiting reactant.

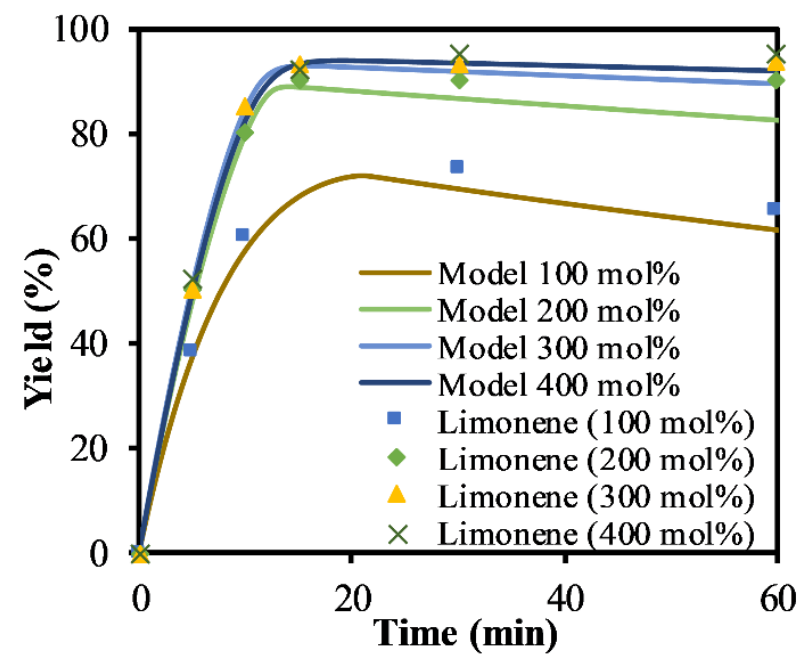

Figure 10. The yield of limonene oxide with an increasing amount of limonene. Reaction conditions: temperature $(323 \mathrm{~K}), \mathrm{H}_{2} \mathrm{O}_{2}(1.25 \mathrm{M}), \mathrm{Na}_{2} \mathrm{WO}_{4}(0.006 \mathrm{M})$ and $\mathrm{H}_{2} \mathrm{SO}_{4}(0.04 \mathrm{M})$. The lines are fitted to the kinetic model by using Equations (3)-(8) and the rate constant in Table 1. 
Figure 10 shows the increasing yield of limonene oxide when the amount of limonene is increased up to $400 \mathrm{~mol} \%$. At the equimolar amount of limonene to $\mathrm{H}_{2} \mathrm{O}_{2}$ (100 mol\%), the maximum yield achieved is only $73 \%$. In this condition, the exothermic temperature not only decomposes $\mathrm{H}_{2} \mathrm{O}_{2}$ but increases the rate of hydrolysis which gradually consumes limonene oxide. However, the yield of limonene oxide is increased to $95 \%$ at $100 \%$ selectivity within 15 minutes reaction time by increasing the limonene amount up to $400 \mathrm{~mol} \%$. Isothermal condition was able to be achieved as the large amount of limonene helps mitigate the exotherm. Interestingly, there is no formation of bisepoxide, and no limonene diol is detected when limonene is used in a higher ratio (> 200 mol\%). This result is due to the rapid rate of formation of limonene oxide, which fully utilises the oxidant present in the system. This also prevents further epoxidation to bisepoxide. Due to the lower acid concentration used at $0.04 \mathrm{M}$, the epoxides remain stable throughout the reaction time, and no limonene diol is formed.

The kinetic model validates the experimental data, especially at more than 300 mol\% of limonene. The model is able to predict $93 \%$ of the limonene oxide yield, which is remarkably close to the percentage in the experimental data $(95 \%)$. However, at a limonene amount of $200 \mathrm{~mol} \%$, the model predicts the formation of bis-epoxide (5\%), which is not observed in the experimental data. Due to the absence of a solvent and the increased molar ratio of limonene to $\mathrm{H}_{2} \mathrm{O}_{2}$, the reaction temperature is slightly exothermic at limonene amount of less than $200 \mathrm{~mol} \%$. This situation causes the initial reaction rate to be slightly higher than the prediction by the model, which uses a rate constant at 323 K. 
From this result, rapid production of limonene oxide in short reaction time could be achieved in a solvent-free environment using a single-step addition of oxidant as opposed to the typical drop-wise method. The biphasic mixture allows the easy separation of the product from the cheap catalyst. The absence of a solvent reduces the purification steps required, while excess limonene would be recycled. Further improvement of the process will involve the recyclability of the catalyst and the development of a continuous process.

\subsection{Conclusions}

Limonene epoxidation using green $\mathrm{H}_{2} \mathrm{O}_{2}$ has been performed by using a tungstenbased polyoxometalates. It has been demonstrated that the epoxidation of limonene could be performed solvent-free at a high yield and selectivity by using limonene in stoichiometric excess (versus $\mathrm{H}_{2} \mathrm{O}_{2}$ ) with a single-step addition of the oxidant. The developed process reveals a potentially high throughput where $95 \%$ conversion of $\mathrm{H}_{2} \mathrm{O}_{2}$ could be achieved with $100 \%$ selectivity towards limonene-1,2-epoxide within a short reaction time ( $\sim 15$ minutes). The addition of $\mathrm{Na}_{2} \mathrm{SO}_{4}$ has been shown to inhibit the hydrolysis of epoxide. The selectivity towards limonene-1,2-epoxide is $100 \%$ when enough $\mathrm{Na}_{2} \mathrm{SO}_{4}$ is used to saturate the aqueous phase. Using the correct acid concentration suppressed the formation of any by-products. The study of the reaction kinetics shows a first-order reaction with respect to limonene. A predictive kinetic model has been developed, with a high level of agreement with the experimental data. Overall, this study has demonstrated that rapid limonene epoxidation can be performed solvent-free at an almost stoichiometric yield by using a single-step addition of oxidant with the judicious 
choice of operating conditions. The identified conditions should lead to a rapid and efficient process, with a significantly improved atom economy.

\section{Conflict of interest}

There are no conflicts of interest to declare

\section{Acknowledgements}

The lead author expresses his gratitude for the financial support from the Engineering and Physical Sciences Research Council (EPSRC) grant (Sustainable Polymers, grant number EP/L017393/1) and the Ministry of Higher Education, Malaysia. 


\section{References}

1. M. N. Belgacem and A. Gandini, Monomers, Polymers and Composites from Renewable Resources, Elsevier, The Boulevard, Langford Lane, Kidlington, Oxford OX5 1GB, UK, 2008.

2. W. F. Erman, Chemistry of Monoterpenes, Marcel Dekker, New York, 1985.

3. A. Calogirou, B. Larsen and D. Kotzias, Atmospheric Environment, 1999, 33, 1423-1439.

4. A. J. Silvestre and A. Gandini, in Monomers, Polymers and Composites from Renewable Resources, Elsevier, 2008, pp. 17-38.

5. N. Fdil, A. Romane, S. Allaoud, A. Karim, Y. Castanet and A. Mortreux, Journal of Molecular Catalysis A: Chemical, 1996, 108, 15-21.

6. P. T. Anastas and M. M. Kirchhoff, Acc. Chem. Res., 2002, 35, 686-694.

7. H. Mimoun, CHIMIA International Journal for Chemistry, 1996, 50, 620-625.

8. C. Chapuis and D. Jacoby, Applied Catalysis A: General, 2001, 221, 93-117.

9. K. Bauer, D. Garbe and H. Surburg, Common fragrance and flavor materials: preparation, properties and uses, John Wiley \& Sons, 2008.

10. M. Bähr, A. Bitto and R. Mülhaupt, Green Chem, 2012, 14, 1447-1454.

11. H. Morikawa, M. Minamoto, Y. Gorou, J.-i. Yamaguchi, H. Morinaga and S. Motokucho, B Chem Soc Jpn, 2017, 91, 92-94.

12. O. Hauenstein, M. Reiter, S. Agarwal, B. Rieger and A. Greiner, Green Chem, 2016, 18, 760-770.

13. C. Martín and A. W. Kleij, Macromolecules, 2016, 49, 6285-6295.

14. M. Pagliaro, A. Fidalgo, L. Palmisano, L. M. Ilharco, F. Parrino and R. Ciriminna, 2018.

15. C. Li, M. Johansson, R. J. Sablong and C. E. Koning, European Polymer Journal, 2017, 96, 337-349.

16. C. M. Byrne, S. D. Allen, E. B. Lobkovsky and G. W. Coates, Journal of the American Chemical Society, 2004, 126, 11404-11405.

17. M. Reiter, S. Vagin, A. Kronast, C. Jandl and B. Rieger, Chemical science, 2017, 8, 1876-1882.

18. K. Ambroziak, R. Mbeleck, B. Saha and D. Sherrington, Int J Chem React Eng, 2010, 8, 1-13.

19. A. J. Bonon, Y. N. Kozlov, J. O. Bahú, R. M. Filho, D. Mandelli and G. B. Shul'pin, J Catal, 2014, 319, 71-86.

20. M. V. Cagnoli, S. G. Casuscelli, A. M. Alvarez, J. F. Bengoa, N. G. Gallegos, N. M. Samaniego, M. E. Crivello, G. E. Ghione, C. F. Pérez, E. R. Herrero and S. G. Marchetti, Applied Catalysis A: General, 2005, 287, 227-235.

21. S. G. Casuscelli, M. E. Crivello, C. F. Perez, G. Ghione, E. R. Herrero, L. R. Pizzio, P. G. Vázquez, C. V. Cáceres and M. N. Blanco, Applied Catalysis A: General, 2004, 274, 115-122.

22. L. Charbonneau and S. Kaliaguine, Appl Catal a-Gen, 2017, 533, 1-8.

23. M. G. Egusquiza, C. I. Cabello, I. L. Botto, H. J. Thomas, S. Casuscelli, E. Herrero and D. Gazzoli, Catalysis Communications, 2012, 26, 117-121.

24. Y. Mahha, L. Salles, J. Y. Piquemal, E. Briot, A. Atlamsani and J. M. Bregeault, J Catal, 2007, 249, 338-348.

25. A. L. Villa, F. T. A. and C. M. de Correa, Journal of Molecular Catalysis A: Chemical, 2002, 185, 269-277. 
26. A. Pena, S. Veiga, M. Sapelli, N. Martínez, V. Márquez, E. Dellacassa and J. Bussi, Reaction Kinetics, Mechanisms and Catalysis, 2012, 107, 263-275.

27. R. B. Zapata, A. L. Villa and C. M. de Correa, Ind. Eng. Chem. Res., 2009, 48, 647-653.

28. R. B. Zapata, A. L. Villa and C. M. de Correa, Ind Eng Chem Res, 2006, 45, 45894596.

29. E. Santacesaria, A. Renken, V. Russo, R. Turco, R. Tesser and M. Di Serio, Ind Eng Chem Res, 2012, 51, 8760-8767.

30. G. Grigoropoulou and J. H. Clark, Tetrahedron Lett, 2006, 47, 4461-4463.

31. C. Venturello and R. D'Aloisio, J. Org. Chem., 1988, 53, 1553-1557.

32. G. Grigoropoulou, J. H. Clark and J. A. Elings, Green Chem, 2003, 5, 1-7.

33. D. C. Duncan, R. C. Chambers, E. Hecht and C. L. Hill, Journal of the American Chemical Society, 1995, 117, 681-691.

34. Y. Ishii, K. Yamawaki, T. Ura, H. Yamada, T. Yoshida and M. Ogawa, J Org Chem, 1988, 53, 3587-3593.

35. H. Hachiya, Y. Kon, Y. Ono, K. Takumi, N. Sasagawa, Y. Ezaki and K. Sato, Synthesis-Stuttgart, 2012, 44, 1672-1678.

36. G. Yadav and A. Pujari, Organic Process Research \& Development, 2000, 4, 8893.

37. G. Yadav and D. Satoskar, Journal of the American Oil Chemists' Society, 1997, 74, 397-407.

38. K. Kamata, K. Yamaguchi and N. Mizuno, Chemistry-A European Journal, 2004, 10, 4728-4734.

39. M.-L. Wang and T.-H. Huang, Ind Eng Chem Res, 2004, 43, 675-681.

40. K. Takumi, N. Sasagawa, Y. Ezaki, Y. Kon, Y. Ono and K. Sato, 2014.

41. A. M. Hyde, S. L. Zultanski, J. H. Waldman, Y.-L. Zhong, M. Shevlin and F. Peng, Organic Process Research \& Development, 2017, 21, 1355-1370.

42. C. Venturello, E. Alneri and M. Ricci, J. Org. Chem., 1983, 48, 3831-3833.

43. K. Sato, M. Aoki, M. Ogawa, T. Hashimoto and R. Noyori, J Org Chem, 1996, 61, 8310-8311.

44. N. A. Comelli, E. N. Ponzi and M. I. Ponzi, Journal of the American Oil Chemists' Society, 2005, 82, 531-535. 